\title{
Worth Sharing: An Italian Entrepreneur Confronts the Crisis
}

\section{Daniel Van Der Vliet (Smith Family Business Initiative)}

KEYWORDS: Entrepreneurship, Leadership,

Restaurants, crisis management.

Michael Cortelletti, owner and "Guardian Angel" of Food Democracy(http://fooddemocracy.it/en/) in Verona, Italy, has seen the affects of COVID-19 first hand, both as a business owner, and as a resident of Verona, Italy. As an alumni of Cornell, Michael had agreed to host a contingency of students who were slated to visit Italy during Cornell spring break in April of 2020 for a "Family Businesses of Italy" trek. The trek, led by the Smith Family Business Initiative, would begin in Milan and travel through Verona and conclude in Rome. After consulting with Michael during the early days of the Italy outbreak in late February, we decided to cancel that trek. Much has continued to unfold in that time, both in Italy as well as worldwide. Michael's insights here, originally published in his blog (https://www.linkedin.com/pulse/entrepreneurship-timecoronavirus-michael-cortelletti/), are honest, forthright and at times painful. Yet, as a business owner, he demonstrates a bias for action and compassion for both his employees and customers.

\section{Learnings From the Front Line}

By Michael Cortelletti

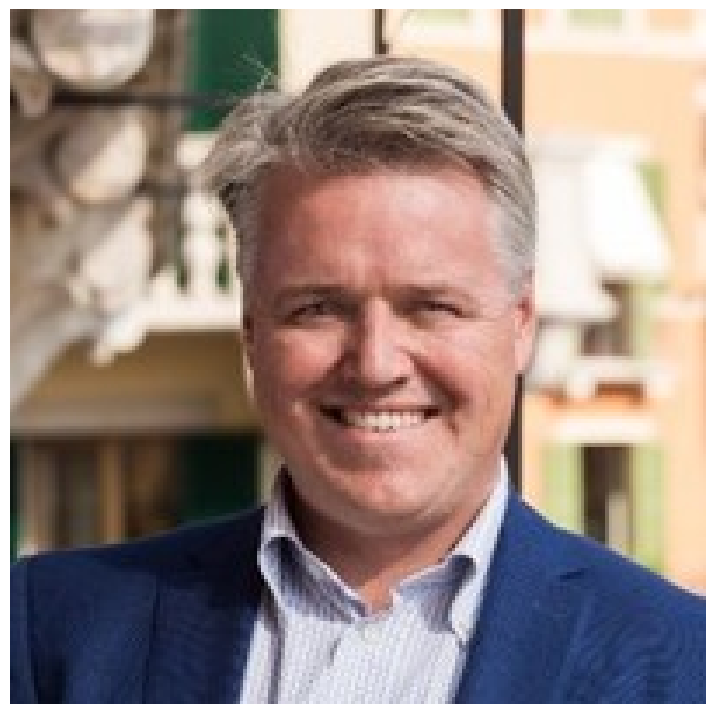

VERONA, ITALY, March 16, 2020 -- This was a contingency plan I did not want to execute. A worst-case scenario that I accurately predicted, but never thought would actually come true. I was sitting in one of my restaurants and reading news from Wuhan in China. And I remember thinking to myself: "The probability of this happening here in Italy are very low, but if it happens the effect will be devastating for tourism and hospitality: I must have a plan for a worst-case scenario, just in case." And thus, I started to put in motion a series of steps which as of today have preserved the health and safety of my team and the solvency of my business. The story is still unfolding. I'm writing this on the 16th of March and the number of infected people is still growing steeply, the deaths are mounting and Coronavirus is becoming a challenge around the world, beyond the narrow confines of Italy.

I've been running my business with an eye on Coronavirus in the last two months now. And in the past few weeks it has become my absolute focus. Today I want to share with you the decisions I took so far and the learning, both positive and negative, which I accumulated in such short time. I believe this is more interesting than reflecting back after the crisis has gone.

Copyright (C) 2020 The Authors. Entrepreneur \& Innovation Exchange is published at EIX.org. This is an open access article under the terms of the Creative Commons Attribution-NoDerivs License, which permits use and distribution in any medium, provided the original work is properly cited and 
Afterwards we're all the wiser, and the crisis will become suffused with the memory of heroism and with the awareness of the outcome.

Today I'm writing with the urgency of the front line. l've developed my strategy and I'm in the middle of combat. It truly feels like a war zone and military metaphors come to mind. Everything is still open: will somebody in my team fall ill with Coronavirus? Will I suffer myself from the disease? If so, will we recover our health? When will I be able to open my restaurants again? How will the economy recover? Will we soon have a cure or will we long live under the fear for new outbreaks of coronavirus? How long will it be until a reliable vaccine is available? How will my company survive the crisis and adapt to a changing environment? All these questions are still open. And I believe this makes my narrative more interesting. Because what seems right in this moment, might turn to have been a mistake tomorrow. And vice versa. And therefore, I also know this is just the first installment: in months, l'll have to get back to this, review it and complete it with what I'll be experiencing and learning soon.

Around the 10th of January first news emerged from China reporting about a new SARS outbreak. After a few days, I learned a new name: Coronavirus. And also, two new facts: one reassuring, the other worrying. The Coronavirus was definitely not as lethal as SARS had been, but much more contagious. The sight of the empty streets of Wuhan got me moving. I could feel a tremendous threat for tourism and for my restaurants. But the probability of it happening in Italy seemed extremely low. Thus, I decided to strike a balance: I would move immediately to protect my business, but only taking actions that would not disrupt operations for my team and service to customers. I kept my worries to myself and to my two most senior managers and started working behind the scenes. I did not want to raise unnecessary fears.

My first step was to postpone a number of investments that were planned in my various restaurants. I rescheduled to November a new lightning system at Casa Mazzanti Caffè, citing the fact that business was very brisk and I did not want the installation to disrupt it. So better move it directly to the traditionally rainy and quiet month of November. I adopted the same line of argument also to postpone the installation of new furniture and equipment at La Costa in Bra as well as the upgrade of the air conditioning at Ristorante Olivo
1939. Now the cash I saved in these early days is indeed very useful. But I also played for time on some new hires and on the printing and promotion of the summer menu.

What I was doing was akin to taking position for a pistol duel: I took care to offer as little room for attack as possible. All the while carrying on and sending a positive outlook to my team. But this was not enough: I also needed to start aiming to be ready for my shot in the duel.

Therefore, I played in my head what the worst scenario was and settled on this: Coronavirus could reach Verona and we could face up to two months of closure and two months of slow recovery. I thus decided I needed a plan to ensure enough liquidity to hold out for four months of no business whatsoever. That would keep me on the safe side of my worst-case scenario. The plan included changing operations to focus on costs, calling in additional financing, engaging suppliers and landlords to change payment terms. I had now taken position and aim and was ready for the duel. But I still believed the challenger would simply not show up for the duel.

\section{Learning 1: If your gut feeling for your own business tells you there is a potential threat, trust your instinct and refocus your resources without yet disrupting daily operations. Worst case, you're wrong and you've only created a lot of work for yourself.}

But the challenger did show up. And despite having planned for it, I was surprised. Things took indeed a different turn when the first case of Coronavirus appeared in Italy. Everything became real. I saw the news in the morning Friday the 20th of February. I was in the Dolomites, skiing with my son. After reading the report, I went alone on the empty slopes. Skiing, like sailing, helps me focus my thoughts and devise robust plans. Perhaps it's the speed and the movement, the clear air or the closeness with nature. But sliding on the snow or through the waves is my very personal form of meditation.

The same day I contacted my largest suppliers and my 
banks. I called each of my key suppliers, asking for a change in my payment terms and negotiating for generous extensions. I was transparent with my motives. I stressed it was a precautionary measure. Since l'm disciplined in my payments and known within the community as reliable, a "man of his word", I encountered great willingness by all suppliers to support my business. Although in most cases accompanied by some incredulity. At the same time, I outlined to my banks my assessment of the situation and started procedures to increase significantly my credit lines. The banks were more reluctant as they did not see the risk yet, but I was able to leverage my good credit standing. Business was still running extremely well. We had a strong winter with cumulative growth of $12 \%$ over the last year. In this context, it was difficult to think in terms of downturn. But nonetheless I did and the early timing was critical. Within a week two banks out of three had already approved my requests. And today, two weeks later, the last bank joined the ranks.

\section{Learning 2: Move early and with transparency to alert key stakeholder to shore up support. If you have a foundation of trust to call upon, everything is easier. These are the moments when all the investment in trust earns you a critical return.}

But the most delicate moment was still ahead of me. The single most important one: meeting my team, alerting them of the risk and at the same time providing a credible reassurance about their personal safety and the safety of their jobs. Also, getting their support for a new operation built around a very different single focus: reducing costs.

The work done so far with regards to investments and hires, with suppliers and banks was only leading to this moment. I had to be able to tell my team how safe their job was. And as I have a strict rule with myself of promising only what I can keep, I needed to be certain. On the Wednesday the 26th of February, I had enough elements to confirm my team that I could continue paying their salary even through four months of closure. This seemed enough for me and thus I decided to meet them personally and break the news. But I could not meet them all at once. The virus was spreading in Italy, and holding a meeting with more than twenty people would have been irresponsible. Thus, first I met my management team. And then the rest, split across three days in smaller groups. The message was simple: we're facing a serious crisis, with up to four months of closure or extremely poor sale, but your jobs are safe if you help me implement a new plan.

The new plan was not without sacrifices for my team. I told them they would be asked to take vacation days, to forgo overtime and to focus operations around costs. No more maintenance calls and ordering only the bare minimum of each product, accepting that we might run out of some items. My team was initially surprised. Despite the number of cases growing fast by the day, they still did not worry. They still did not think it would affect us. They still did not think the virus would reach our doorsteps. You never do. None of them thought we might truly have to close. In hindsight, these timely meetings were crucial. They alerted my team to the challenge ahead and rallied them around my plan. As things unfolded they were worried, but never really scared. While some of my colleagues had issues with people not even showing up for work, my team stood united and focused until the government asked us to close. And they are in good spirits even now that we are in contact only through our smartphones.

I believe a critical point was that before even addressing the business risks and their job safety, I addressed at length the health risk and their personal safety. My meetings in those days were first and foremost about providing reliable information about the Coronavirus, and only then providing an update about the business situation and the upcoming steps. To do this I had to get valid information about the virus. Fortunately, on the 14th of February a report was published analyzing the first 44.000 cases in China. Further, the WHO had published a number of practical recommendations for reducing the risk of contagion. So, while I was working with suppliers and banks to secure additional cash, I also studied all I could find at the time about the Coronavirus and developed a set of recommendations for my team and new procedures for our service.

At our meetings, I stressed how the mortality rate was disproportionate among the elderly, and those with heart or respiratory conditions as well as diabetes and high blood pressure. All employees that fell under these risk factors were immediately asked to stay at home. This was very hard for the few affected. At that time, Italy had 
still few cases, although they were growing fast. But now they thank me for it. Further, I asked them to take good care of the elderly in their families and keep them isolated. And at the same time reassured the young and healthy about their prospects, as well as young parents about the safety of their kids. The most redeeming feature of the Coronavirus is the fact that children seem to survive it unscathed, which is not the case for flu or other contagious diseases. In addition, during those days I installed dispensers with disinfectant across my restaurants for use by customers and employees alike. Again, initially customers were perplexed or even irritated, while in the last days of operations they were thankful.

As the closures were implemented, I established a system of communication through smartphones for my team to stay connected. For people used to meet in person and work through personal contact, this was a difficult transition. The idea is to keep in connection while physically separated, but also have an early warning system should any of us fall ill and need support. Many of my employees moved to Verona for their jobs and have no network of support here. Thus, the company has to step in. And as we now are into our fifth day of closure, this has proven invaluable. So far all are healthy and mostly in good spirits, although there are some legitimate moments of worry and discomfort.

Learning 3: Your team is your most important ally. It's not a resource, it's not capital: it's actual human beings who choose to follow you and bind their lives to you. For this choice they deserve respect, and most importantly the truth.

At this point I faced a stark personal decision. Did I want to continue staying in Verona? Or should I go to Berlin to my family? Should I stay and risk being cut off from my wife and kids for an indefinite period of time? Or should I go to them and run my business from afar as we progressed towards an inevitable closure? A bit of background.

I own and lead Food Democracy (www.fooddemocracy.it), a group of five restaurants and an ice cream shop in Verona. But my home is in Berlin. My wife and kids live there. And I commute between
Verona and Berlin. Between Italy and Germany. After all, it's the European Union. But our freedom to travel was being curtailed by the day. I had three responsibilities to weigh: towards the community, towards my team and finally towards my family. In Italy the Coronavirus epidemic was spreading faster than in Germany: I was healthy, but did I want to risk adding to the contagion in Germany by travelling? My team was now trained and informed, but things could change suddenly: was it fair to lead them from afar as the situation in Verona would probably deteriorate faster than in Berlin? My wife and kids were in Berlin with a network of friends, but without any other family or relatives: shouldn't I be with them in case somebody fell ill? Clearly, these were conflicting responsibilities.

And I could resolve them only with the support of my wife and business partner: Stefania. After we talked at length she clearly said: «Our team needs your presence more than we do right now». And that sealed it. I had left Berlin on the 25th of February and was already more than a week in Verona. On the 8th of March my wife and I assessed correctly that within the next few days travel would become impossible and we came to the conclusion that I should stay.

Now it's the 16th of March and I have no idea when I'll be able to see my wife and kids again. Perhaps for Easter? Hopefully. But as my team and customers realized that I was staying in Verona and that I would be stuck with them, I experienced the most amazing outpouring of support and gratitude. They would have understood if I would have left. But seeing the leader stay in place and share the slow descent into the complete closure of social and economic life has created a bond that is difficult to describe. I'm sure this will be a tremendous resource for all of us when we'll come together again to start over.

\section{Learning 4: Leadership is about choices and example. And in times of crisis, a leader must make sacrifices in order to ask for sacrifices.}

\begin{abstract}
The slow progression of closures has started. First eight small cities were completely sealed off from the rest of Italy. Then new rules for social life in Italy were issued. Keeping at least a distance of one meter in a country
\end{abstract}


used to hugging and kissing at each encounter was really difficult. As for our business, the first test was the prohibition to serve over the counter: only table service, and seating guests, you guessed it, at least one meter apart. The beloved coffee sipped quickly while carelessly placing your elbow on a bar counter, be it shabby or stylish, was gone.

Then the restrictions accelerated. Travel in many parts of the country became possible only for business and health reason. A few days later this was extended to the entire country. Restaurants were asked to close at night after 6 PM. A few days later they were asked to close altogether. Only delivery service is now possible. The challenge of this is difficult to understand for people not living in Italy. We love our cities, our streets, our piazzas. We spend most of the day out and about. Most of us have breakfast at one of the innumerous bars. Not to mention lunch breaks and dinner. Italy has one of the highest density of bars and restaurants per capita in the world.

In 2009, I came back to Italy after twelve years living and working in the USA and Germany. And at the beginning I was overwhelmed by the insistence Italians had to meet me in person even for the most trifle reason. Over the years, I've appreciated how important this is to hold together the network that spans our society. And now this had to stop. It was painful. It still is.

And it's no surprise that now, every evening, we open our windows, step on our balconies and make music. People here simply crave being together. Despite being probably the most individualistic and unpredictable people l've ever met in my many years of travel.Confronted with the advance of the virus and the progressive closures afterwards, I had to take a difficult decision: wait for the Government to ask me to close my restaurants or do it sooner? The instinctive reaction would have been to close right away. And many of my colleagues did so. Ironically, many colleagues who in the last week of February organized events to lure people out and fight the growing fear for the virus, in the first week of March already closed their restaurants. Again, I asked myself where my responsibilities lie.

First and foremost was the question of safety for my team. I looked at the steps taken so far and felt reassured that everything possible had been done. I had already asked those workers with a risk factor, who would probably suffer stronger symptoms should they be infected by the Coronavirus, to stay at home and live as isolated as possible. Further I had established procedures for social distance in the restaurants and in the office, as well as procedures for increased cleaning and sanitizing both of ourselves and the environment we worked in. At this stage, when social life in the country was still unrestricted, closing my restaurants and letting my employees at home conducting an active life would not have added anything to their safety. In fact, it might have exposed them to contagion should they have chosen to spend the unexpected leisure time in the company of friends or relatives. But there was also the question of customers. Was I actually adding to their risk of contagion by staying open and in business? looked at our operation and realized our customers were quite disciplined in respecting the new rules: sanitizing their hand upon entering the restaurant, keeping the distance when seated and accepting that no counter service was possible. But was it enough? Wouldn't it be safer to just close? After all, there were very few customers left in any case and we were already working at a loss.

A week after the first case was registered in Codogno, sales dropped by $20 \%$ over the previous year. The following week sales dropped further to roughly $50 \%$ and in the last week before the definitive closure sales were $80 \%$ less than in 2019. But short term economics should not be the only factor. At the core, running a restaurant means offering a public service.

After all, without restaurants where do people working and travelling go to for a glass of water, a coffee or a clean restroom? It always struck me that in Italy restaurants have an obligation to have minimum opening hours and to allow access to their restroom. It underscores the public function of restaurants.

Thinking about this dilemma, it was helpful to picture what would happen if many others would have closed their restaurants on their own volition. I quickly realized that the few open bars and restaurants would become quickly overcrowded, and invariably facilitate a further spread of the virus. What seemed rational for me, would be of harmful for society as a whole. The only way to ensure my closure would not affect negatively my community, was to close when all restaurants where expected to close. At that point, we would go from few customers spread among many restaurants and thus able to both access a basic service and keep the required social distance, to a situation where no 
restaurants would be available and thus only your own home could provide you with those basic services of food and shelter. And at that point the risk for contagion would be truly reduced with no risk of unintended consequences. I came to the conclusion that closing in advance might look good, but is ultimately harmful.

And thus, I stayed open until the end, following to the instructions issued by our health authorities. First I closed those restaurants of mine that did not represent an essential service: Gelateria Impero - because ice cream is a great product but not a necessity of life - and Altro Impero - because it's a gourmet pizzeria and the service it provides can easily covered by the nearby Pizzeria Impero. Second, I closed at night once required, offering a delivery service out of Ristorante Olivo 1939 and Pizzeria Impero. Finally, I closed all restaurants and kept open only the delivery service from Pizzeria Impero. My restaurants are all clustered around the historical center of Verona. Pizzeria Impero alone is able to service all neighborhoods reached by of my other restaurants. Therefore, I could concentrate on this store my efforts in providing a service for those who cannot easily cook at home.

Finally, keeping the delivery service open allowed me also to support my community. I partnered with the Croce Verde in Verona (www.croceverdeverona.org). This is an organization based on volunteers who offers first response and aid to people in need, as well as ambulance transport for the injured and the sick. As you can imagine, in these days the Croce Verde is overwhelmed by the needs of our community. Starting on the 13th of March the Pizzeria Impero provides free lunch and dinner to the stations located in the historical center and at the main hospital. We'll continue until the crisis is over.

This little support allows my team and myself to do what we do best: provide great food, a friendly smile and a moment of respite. Ultimately, this is what we do for our customers too. And what we hope to be doing soon again. And being able to do it for the Croce Verde gives us the feeling that, after all, we are not powerless in the face of this epidemic.

Something can be done, and I want to focus on that. In fact, throughout this difficult time and even now, I continue focusing my personal as well as my company's communication on the positive signs already present today and the silver lining appearing when looking at tomorrow. Even as I planned for the worst turn of events, I kept focusing my communication on the best of possible outcomes. Because I realized that my team and my customers cannot be confronted only with worst case scenarios, contingency plans and risk management. This is important for the mind. But the heart needs hope. Even irrational hope. Because, despite all the darkness and the hard news or just because of them, there is a deep need for hope to find the necessary energy to overcome such daily challenges.

\section{Learning 5: Even if you plan for the worst, you need to communicate for the best. Your team and your clients appreciate your plan for the rain, but want also to hear from you that the sun will shine again. You might be wrong today because it keeps raining, but when the sun comes people will be grateful for having kept hope alive.}

The question today, on this 16th of March, is: where do we go from here? I'm already planning for the period after the coronavirus. The length of the closure is no longer my concern. I already planned for it and I'm simply executing the plan. Now it's more important to prepare the next plan. Regardless of how long the closure will last, the question is how will the recovery be afterwards. Swift and enthusiastic? People deprived of freedom and choices crowding the restaurants? People locked in their homes and confined to their countries travelling again with gusto? Or will the fear linger on and people continue to maintain social distance?

My worst scenario is one of prolonged fear, with occasional outbreaks of the Coronavirus, until finally a vaccine is found in roughly eighteen to twenty-four months. This would mean that we would have two years of decline and disruption in the global travel and tourism. Travel by car to close by destinations will be preferred. Events and crowded indoor places will suffer. But outdoor seating will continue to grow in popularity. Quick dining solutions will be preferred and the customers will look strictly for products and experiences that cannot be replicated at home, neither by themselves nor through delivery.

At the other end of the spectrum, the best scenario is 
that we come out fast and furious from this crisis. A valid cure will be available within few months and a promising vaccine will be already under test. Fear is dispelled and customers hunger for all those things they were deprived of: social connection, travel, events and, obviously, restaurants. I argue that the most likely scenario is not simply a mix of the worst and best scenario: but rather a succession, going from the worst to the best over time. The degree to which the best scenario truly and fully happens will depend, I believe, from the length it will take to go from fear to confidence. If the change is swift, say within three to six months, the recovery will be robust and the renewed confidence could fuel a lot of growth in tourism and hospitality. If the change is slow, say six to twenty-four months, some remnants of fear will have the time to linger and sink in. Most importantly, many players in the industry will have unfortunately folded and closed. The lack of choice then will constrain the recovery in tourism and hospitality.

Obviously, I need a plan for all these options. Let's connect again in three months and compare my thoughts with reality. Am I looking at the right issues here? Will I have the right plan in place? Will I manage to keep my team safe and my business intact? Time will tell. To be continued... 